\title{
A Retrospective Analysis of Nursing Students' Clinical Experience in an All-Male Maximum Security Prison.
}

\author{
Mary T. Bouchaud \\ Thomas Jefferson University \\ Madeline Brooks \\ Thomas Jefferson University \\ Beth Ann Swan \\ Thomas Jefferson University
}

Follow this and additional works at: https://jdc.jefferson.edu/nursfp

Part of the Public Health and Community Nursing Commons

Let us know how access to this document benefits you

\section{Recommended Citation}

Bouchaud, Mary T.; Brooks, Madeline; and Swan, Beth Ann, "A Retrospective Analysis of Nursing Students' Clinical Experience in an All-Male Maximum Security Prison." (2017). College of

Nursing Faculty Papers \& Presentations. Paper 88.

https://jdc.jefferson.edu/nursfp/88

This Article is brought to you for free and open access by the Jefferson Digital Commons. The Jefferson Digital Commons is a service of Thomas Jefferson University's Center for Teaching and Learning (CTL). The Commons is a showcase for Jefferson books and journals, peer-reviewed scholarly publications, unique historical collections from the University archives, and teaching tools. The Jefferson Digital Commons allows researchers and interested readers anywhere in the world to learn about and keep up to date with Jefferson scholarship. This article has been accepted for inclusion in College of Nursing Faculty Papers \& Presentations by an authorized administrator of the Jefferson Digital Commons. For more information, please contact: JeffersonDigitalCommons@jefferson.edu. 


\title{
A Retrospective Analysis of Nursing Students' Clinical Experience in an All-Male Maximum Security Prison
}

\author{
Mary T. Bouchaud, PhD, RN, CNS, CRRN \\ Madeline Brooks, BA \\ Beth Ann Swan, PhD, CRNP, FAAN \\ Author Affiliations: \\ Assistant Professor (Dr Bouchaud) and Professor \\ (Dr Swan), Jefferson College of Nursing, and Work Study Employee (Ms \\ Brooks), Office of Institutional Research, Thomas Jefferson University, \\ Philadelphia, Pennsylvania. \\ The authors declare no conflicts of interest. \\ Correspondence: \\ Dr Bouchaud, Jefferson College of Nursing, Thomas \\ Jefferson University, 130 S 9th St, Ste 867, Philadelphia, PA 19107 \\ (mary.bouchaud@jefferson.edu).
}

\begin{abstract}
Prisons provide an ideal learning experience to prepare prelicensure students with the knowledge and skill set needed for practice in the 21st century. Beginning descriptive evidence demonstrates that correctional health is an innovative community resource to educate nursing students in today's changing model of health care delivery and practice. This article shares results from a retrospective analysis of the perceptions and experiences of nursing students during their community clinical rotation in an all-male maximum security prison.
\end{abstract}

Keywords: community health nursing; correctional health; nursing education; preceptorships; prisons

While health care delivery is moving from hospital to ambulatory and community settings, community-based educational opportunities for nursing students are shrinking because of increased regulatory requirements, competing numbers of nursing schools, increasing student enrollment, and decreasing availability of community resources capable and willing to precept students. Prisons, as microcosms of society, provide an ideal learning experience for the nursing skill set needed for practice in the 21st century, as well as population-based care, cultural sensitivity, and interprofessional efforts to engage individuals in the management of chronic conditions.1-4

There is beginning descriptive evidence that demonstrates that correctional health is an innovative and viable clinical resource to educate nursing students in today's changing model of health care delivery and practice.1 Existing studies describe prisonbased clinical rotations in terms of the working environment and skills gained by health professions students.1,2,4 Educational experiences in correctional settings have been received positively by health professions students,5-7 but few studies exclusively examine student evaluations of such rotations. There exists a need for more current data related to nursing students' clinical experiences in prison and their perceptions of correctional nursing.

For more than a decade, a college of nursing at an urban, academic health center has placed students from a BSN program in state and federal level prisons and juvenile detention centers throughout Pennsylvania and New Jersey. This article shares results from a retrospective analysis of students' perceptions and experiences during a community health clinical rotation in an all-male maximum security prison.

In 2004, the authors' college of nursing began considering alternative solutions to preparing students for community and public health nursing. Two years later, the first group of $8 \mathrm{BSN}$ students signed up to complete their community clinical rotation at a 4000-person, all-male maximum security prison in rural New Jersey. Demand of BSN students for the prison rotation (which was available by request only) continued to grow each year, resulting in waiting lists with as many as 45 students. 1

Students had the opportunity to rotate through 11 healthcare units within the prison. These included outpatient and chronic care clinics, as well as an infirmary and a nursing/palliative care unit. Students also completed learning experiences in the dialysis unit, detention center, and mental health unit. They assisted a physical therapist, an infection control nurse, and a discharge care planner. Students were mentored by the nurse practitioner/wound care nurse in the work release housing unit located outside the prison walls and followed her in rounds throughout the prison. Finally, students had the opportunity, when 
available, to make rounds with the physician and observe robotic telemedicine follow-up visits with inmates diagnosed with neurological conditions such as Lou Gehrig's disease and multiple sclerosis.

\section{Methods}

After institutional review board approval, the researchers used a retrospective design using surveys completed by students from 2006 to 2016. On the last day of the clinical rotation, each student was given a Community Clinical Evaluation survey consisting of qualitative and quantitative questions developed by the regional director of nursing, who oversees all prisons in New Jersey. This survey provided students an opportunity to evaluate, through quantitative ratings on a scale of 1 (poor) to 4 (excellent) and open-ended questions, their experiences during their prison rotation. The survey asked students about their expectations before starting the prison rotation, perceptions of the prison experience upon completion of the rotation, feelings of safety, opinions of correctional nursing, and whether they would recommend this rotation to be continued as a community health site option. In addition, the survey asked students to rate each unit on which they had clinical practice and provide a qualitative comment to support that rating. Surveys were anonymous and had no identifiers. There was a $100 \%$ return rate $(\mathrm{N}=186)$.

\section{Study Procedures}

The survey responses were separated by questions regarding student perceptions before and after the rotation to analyze changes in perceptions over time. The primary author and 2 independent qualitative researchers conducted separate thematic analyses of the data using open coding. The primary author and researchers came to agreement on appropriate themes and definitions. Finally, the qualitative data were coded by main themes, which included general impressions, learning environment, prison environment, nature of medical care, and perceptions of correctional nursing. Quantitative ratings for individual health care units were analyzed using SPSS version 23 (IBM Corp, Armonk, New York).

\section{Qualitative Results}

The survey asked students to describe (1) what they expected of the rotation before their first day, (2) their opinions of the rotation on their last day, (3) their opinions of correctional nursing, and (4) why they would or would not recommend continuing the prison rotation as a community site option. Although 186 students completed the survey, response rates vary by question.

\section{Student Expectations of Prison Rotation Before the First Day}

Of 169 student responses, 156 we recategorized into 4 themes: general impressions $(n=81)$, learning environment $(n=17)$, prison environment $(n=39)$, and nature of medical care $(n=19)$. The remaining 13 responses referenced other topics or more than 1 of the main themes. Although these responses did not fit into thematic categories, they nevertheless reflect the rich variety of topics on which students commented.

Nearly a third of respondents indicated uncertainty or lack of expectations about the rotation (49/169). A number of students were apprehensive about the prison rotation, feeling "nervous," "scared," "intimidated," or worried for their personal safety. Some, however, felt excited or curious about this novel clinical setting. Students generally expected to learn about not only correctional nursing but also the ways in which the prison system operates and affects the delivery of medical care.

Despite students' uncertainty or trepidation about the rotation, most considered it an excellent learning environment that provided a deeper level of experience than "traditional" clinical sites such as hospitals. They commonly expected to perform more "hands-on" interventions they may not be able to do in other environments. Students varied in regard to their perceived roles during the rotation. Some expected to do a great deal of work, in part to "help ease the daily obligations for RNs." Others expected to do little more than "pass meds."

Students' expectations of the prison environment before their rotation revealed generally negative stereotypes of prisons and inmate populations. Students expected the prison to be "dirty," "dark," "violent," or "scary," whereas they believed inmates to be "aggressive," "disrespectful," or carrying a "street attitude."

Of the 19 students who commented on their preconceptions of medical care in the prison setting, 13 expected a limited quality and quantity of care: "I expected that there would be bare-bones health care options." Some expected a simplistic standard of care, with nurses providing only health checks or sick calls. Comments also revealed student perceptions of what type of medical conditions they expected to encounter in the prison setting. Mental health and communicable diseases such as hepatitis and human immunodeficiency virus were thought to be prevalent concerns, whereas few mentioned care for chronic diseases or end-of-life issues. 
Of 165 student responses, 142 were categorized into the same 4 themes: general impressions $(n=72)$, learning environment $(n$ $=19)$, prison environment $(n=37)$, and nature of medical care $(n=14)$. The remaining 23 responses referenced other topics or more than 1 of the main themes.

In contrast to their apprehension before the prison rotation, the vast majority of students described their experience positively. They praised the diversity and depth of experience, as well as the opportunity to observe the "balance" between care delivery and having to comply with strict and regimented prison rules and regulations. Several students highlighted the uniqueness of the prison setting, often characterizing it as a "different world." Only a few students indicated dissatisfaction with the ratio of observation to practice time or with the level of medical care or freedom allowed to inmates.

Regarding learning opportunities, students were highly satisfied with the amount of hands-on skills they practiced, especially compared with rotations in other settings: "I learned more, performed more procedures, than all my previous clinicals combined." Prison staff members were praised for their patience, respect, and willingness to teach. Students also indicated surprise with inmates' respectful conduct.

Students' general perceptions of the prison environment changed dramatically after the rotation. They uniformly praised the safety, cleanliness, and controlled atmosphere of the prison, often describing it as a well-functioning "community" or "society." Staff members were described as "friendly," "courteous," and "professional."

Of the 14 students who commented on their perceptions of correctional health care post-rotation, 11 indicated2 that they were "impressed on amount of care given for medical needs," "amazed," or otherwise pleased by the quality and/or quantity of health care. A few students, however, expressed dissatisfaction in this regard: "I was astonished and baffled that the prisoners receive more health care than people on the outside. I found it very unfair." Despite these perceptions, others noted that inmates "still have the right to be respected" and described the inmate population as an "important community that deserves health care."

\section{Student Perceptions of Correctional Nursing}

Of 172 student responses, 160 we recategorized into 3 themes: general impressions $(n=114)$, willingness to work in correctional nursing $(n=22)$, and challenges in correctional nursing $(n=24)$. The remaining 12 responses referenced other topics or more than 1 of the main themes.

Correctional nursing was described by students in terms of its reputation, value, working environment, responsibilities, and comparison with other settings. Some indicated an interest in pursuing a career in correctional nursing, whereas others described what they saw as insurmountable barriers to this nursing role, such as lack of closeness with patients and knowledge of inmates' crimes. Students described correctional nursing as "vital," "credible," and even "noble," indicating high levels of respect for a nursing role with which many were unfamiliar before this rotation.

They noted the level of autonomy that accompanies correctional nurses' high number of patients and responsibilities: "You don't realize how much they deal with until you spend a day in their shoes. I learned the true definition of autonomy while having clinical here." Several commented on correctional nurses' wide-ranging scope of practice, noting the "diversity of patient population and disease process" encountered on a daily basis. Correctional nursing was frequently compared with nursing in the hospital setting. Students believed that correctional nurses experience more freedom and less pressure than hospital nurses yet have to prioritize safety above patient care.

Twenty-two students stated their desire to work, or willingness to consider working, as a correctional nurse. They could now "see" themselves working in correctional health, drawn by their respect for the specialty and the ability to work with underserved populations. One said, "I would definitely want to work as a correctional nurse after this experience. I learned that you can make a difference in the prison community by delivering optimal patient care to the inmates. You can be compassionate without being 'touchy-feely' with inmates and (by) respecting them." Students' willingness to pursue correctional nursing, however, came with a precondition. Of the 22 students who indicated interest in this area of nursing, half viewed correctional nursing as something to consider only after several years of experience. One student summed up these feelings, saying, "I would never come to correctional nursing directly out of school. However, after experience, I could see myself working (there) as an NP."

For those interested in correctional nursing, a similar number noted challenges that might prevent them from working in this profession, including navigation of the strict boundaries that prevent "closeness" with patients. Many found it difficult to reconcile their role as nurses with knowledge of inmates' backgrounds: "Hard to handle if you know the crime." Some indicated 
that it was morally challenging to trust inmates or provide them with unbiased care: "I couldn't separate my morals from my profession at this point."

\section{Feedback on Continuing Prison Rotation}

Students were asked to explain why they would or would not recommend continuing this rotation as a community health site. All but 1 student recommended continuing the experience in the prison $(n=175)$. They described their experience as positive and unique, one that provided a new aspect of community and public health nursing. Some noted the value of seeing how nurses adapt to the challenges of new environments: "Being able to learn about nursing care in the prison community broadened my horizon of just how much nurses can do." Students also prized the novelty of the prison setting, noting that it offered a glimpse into a world seen rarely outside media portrayals: "Most people get their opinion of prison based on what they see on TV; this rotation gives the opportunity to see what prison is really like."

Students considered the rotation valuable in that it taught skills that could be gained only in a prison setting. One said, "I think a rotation here teaches how to react without the availability of unlimited supplies in a contained environment." Others focused on the opportunity to practice soft skills such as cultural sensitivity and the provision of nonjudgmental care, noting that the rotation "promotes humane treatment of all people, regardless of their personal circumstances." Many recognized the value of exposure to the inmate population, particularly in reducing bias or informing future interactions with current or previous inmates.

\section{Quantitative Results}

The survey used an open-ended question that asked students to report on their feelings of safety within the prison and while interacting with inmates on various health care units. Responses were categorized and totaled (Table). Students were also asked to rate their experience in each health care unit on a scale of 1 (poor) to 4 (excellent) and provide a qualitative comment to support their rating.

\section{Safety Ratings}

Eighty-seven percent of the respondents $(n=156)$ reported feeling safe while in the prison, and $13 \%$ conditioned their feelings of safety, indicating that they felt "mostly safe" or safer as time went on. Ninety-seven percent of the respondents who spent time in the dialysis unit (which was managed by an outside company) reported feeling safe while interacting with inmates there. Nearly all of the students $(n=155,98 \%)$ felt safe while interacting with inmates on other units. Some noted occasional feelings of discomfort, particularly in the presence of multiple inmates. Three students indicated that they felt unsafe in various units (Table).

\section{Health Care Unit Ratings}

The 3 highest-rated health care units in terms of student experience were physical therapy (PT) (M 3.9), infection control nursing (ICN) (M 3.7), and the extended care unit (ECU) (M 3.6). Students rated their experience in the mental health unit lowest (M 3.2). The PT, ICN, and ECU were likely rated favorably because students were impressed by the physical therapist they observed, and the ICN and ECU provided ample clinical experience with purified protein derivative skin tests and wound care, respectively. Students indicated dissatisfaction with the lack of active practice time in the mental health unit.

Table. Student Safety and Recommendation for Prison Rotation

Items

Did you feel "safe" while in the prison?

Yes

Yes, with supportive comments

Yes, mostly or conditional

Did you feel "safe" while interacting with prisoners in the dialysis unit?

Yes

Yes, with supportive comments

Yes, mostly or conditional

Did you feel "safe" while interacting with prisoners in other units? $\mathrm{n}(\%)$

$99(55.0)$ 
Yes

$140(88.6)$

Yes, with supportive comments

Yes, mostly or conditional

Noa

a Two students indicated that they felt unsafe in the detention center, and 1 student indicated that he/she felt unsafe in both the detention center and the extended care unit.

\section{Discussion}

The survey data indicate that nursing students found prisons to be a safe, beneficial, and unique setting for clinical learning. This supports the studies of Ruman et al 5 and van de Mortel et al, 7 in which nursing students praised their clinical experiences in prisons. Prison rotations seem to provide breadth and depth of nursing experience, while reinforcing skills in community health and efficient delivery of care in restricted settings.

Students demonstrated their willingness to complete a rotation in correctional settings, despite initial feelings of uncertainty or fear, reflecting the findings of Ruman et al.5 On the contrary, many were attracted by the unique nature of the rotation, as revealed in numerous comments describing it as a "once-in-a-lifetime experience." The rotation seemed to decrease students' fears associated with practicing in nontraditional or intimidating environments-a valuable skill given the call to better equip nursing students for practice and advocacy across a variety of community settings.1,8

Students also observed the high degree of nursing autonomy necessitated by prisons' wide range of patients and medical conditions. Indeed, many students were surprised by the variety of care provided in the prison. They witnessed a specialty area of nursing that allows more autonomy and scope of practice, despite working with more daily regulatory restrictions and fewer available on-site resources. The Institute of Medicine calls for nurses to step into the "full extent of their education and training" to broaden the continuum of care and increase efficiencies.8 Prisons seem to provide ample experience in these competencies.

Students generally understood the importance of better understanding the inmate population, especially regarding future encounters in the health care system: at least $95 \%$ of all state prisoners will be released at some point. 9 Therefore, illness among the prison population constitutes a public health problem that requires attention during and after incarceration.10 $\mathrm{A}$ prison rotation has the potential to help reduce personal stigma against inmates, a unique skill that has public health implications inside and outside prison walls. Perceived stigma from health care providers can increase the risk of stress-related illness, reduce quality of life, or cause patients to delay or avoid seeking medical care. 11 These effects may be compounded by the stigma of criminal justice involvement, which can predict social withdrawal and poor community adjustment post-release.12 Students' perceptions of correctional nursing revealed the societal value-and stigma-of serving this population, as well as the contrast between inmates as patients and prisoners. One described the duality of correctional nursing, saying, "The rotation was intriguing to see the dichotomy between people who treat this as a lab and the people as inmates, and the people who treat this as a career and the people as patients."

\section{Limitations}

The survey did not collect demographic data, which could have revealed differences in responses. It also did not include questions to discern the motivating factor(s) for students (most of whom are female) who request the community clinical rotation in an all-male maximum security prison. A more comprehensive survey should be developed for future use at clinical sites. Finally, this study's sample may be biased positively because students had to request the prison rotation and may therefore reflect fewer misgivings about correctional settings than the general population of nursing students.

\section{Implications}

By offering this unique clinical rotation in a prison, nursing students were exposed to an area of nursing practice they would never have the opportunity to know about or experience. Therefore, a prison rotation can potentially bolster the number of students who become community and population health nurses in correctional settings. 3 Another result of placing nursing students in prison settings for clinical rotations is that students gain expertise in the new skill sets for 21st century practice that include assessment and prevention, population-based care, professionalism, and bias reduction. 
A prison rotation offers a new avenue through which to prepare population-focused nurses who can function in a rapidly changing health care landscape. The benefits extend to not only society but also individual students as well. This value is perhaps best summarized by 1 student who said, 'I entered [the prison] feeling like little more than a student. Today I feel ready to call myself a nurse."

\section{Acknowledgment}

The authors acknowledge Momo Nakagawa, BS, Research Data Analyst, Office of Institutional Research, Thomas Jefferson University, for her contributions in transcribing and analyzing the qualitative data.

\section{References}

1. Bouchaud MT, Swan BA. Integrating correctional and community health care: an innovative approach for clinical learning in a baccalaureate nursing program. Nurs Forum. 2017;52(1):28-49.

2. Boyd SM, Mott D. Taking students to prison. J Nurs Educ. 1999;38(5):235-237.

3. HaleJF,HaleyHL,JonesJL,BrennanA,BrewerA.Academic-correctional health partnerships: preparing the correctional health workforce for the changing landscape-focus group research results. J Correct Health Care. 2015;21(1):70-81.

4. Felter-Wernsdorfer R, Nass J, Smith JW. Educational experience in a correctional facility setting. J Midwifery Womens Health. 2000;45(4):314319.

5. Ruman J, Hyde R, Brumfield B, Nagel J. Linking correctional healthcare to higher education: creating educational opportunities for nursing students. J Correct Health Care. 1999;6(2):223-233.

6. Alemagno SA, Wilkinson M, Levy L. Medical education goes to prison: why? Acad Med. 2004;79(2):123-127.

7. van de Mortel TF, Needham J, Barnewall K, Djachenko A, Patrick J. Student nurses' perceptions of clinical placements

in Australian Prison Health Services: a mixed methods study. Nurse Educ Pract. 2017;24:55-61.

8. Institute of Medicine. The Future of Nursing: Leading Change, Advancing Health. Washington, DC: The National Academies Press; 2011.

9. Hughes T, Wilson DJ. Reentry trends in the U.S.: inmates returning to the community after serving time in prison. Bureau of Justice Statistics Web site. Available at https://www.bjs.gov/content/reentry/reentry.cfm. Accessed May 20, 2017.

10. Kinner SA, Wang EA. The case for improving the health of ex-prisoners. Am J Public Health. 2014;104(8):1352-1355

11. Earnshaw VA, Quinn DM. The impact of stigma in healthcare on people living with chronic illnesses. J Health Psychol.2012; $17(2): 157$ 168.

12. Moore KE, Tangney JP. Managing the concealable stigma of criminal justice system involvement: a longitudinal examination of anticipated stigma, social withdrawal, and post-release adjustment. J Soc Issues. 2017;73(2):322-340 